\title{
Lumpy Labor Adjustment as a Propagation Mechanism of Business Cycles
}

\section{Fang Yao*}

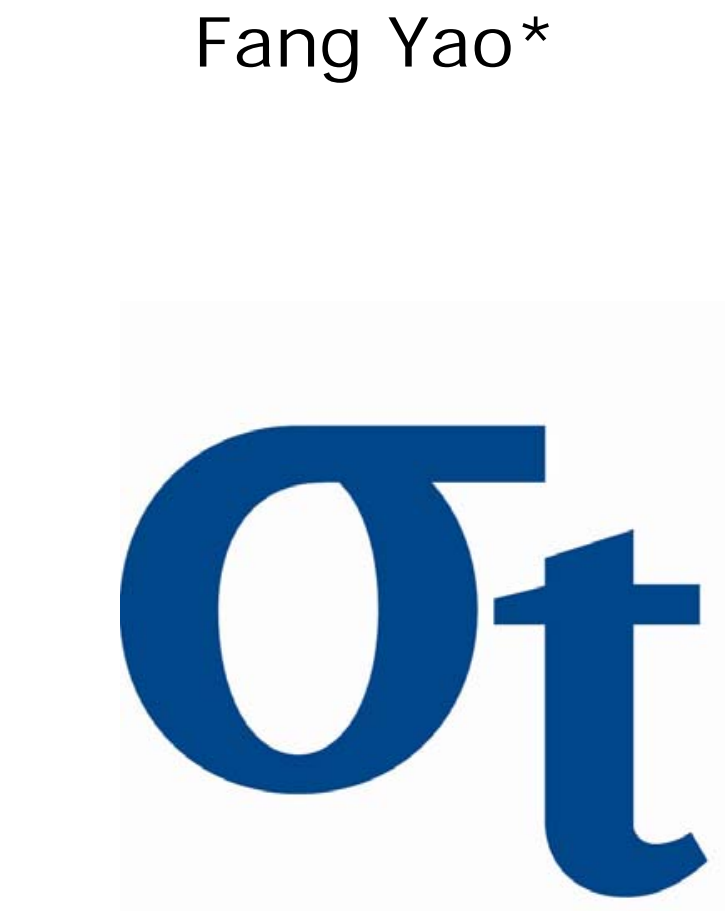

* Humboldt-Universität zu Berlin, Germany

This research was supported by the Deutsche Forschungsgemeinschaft through the SFB 649 "Economic Risk". 


\title{
Humboldt-Universität zu Berlin
}

Wirtschaftswissenschaftliche Fakultät

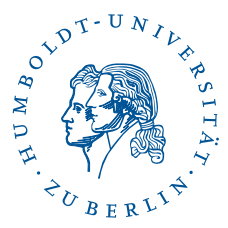

Institut für Wirtschaftstheorie II

\section{Lumpy Labor Adjustment as a Propagation Mechanism of Business Cycles}

\author{
Fang $\mathrm{Yao}^{1}$
}

\begin{abstract}
Affiliation: Institute for Economic Theory Humboldt University of Berlin

E-mail: $\quad$ yaofang@rz.hu-berlin.de

Date: $\quad$ 18th May 2008
\end{abstract}

\footnotetext{
${ }^{1}$ I am grateful to Michael Burda, Stephan Fahr, Tom Krebs, Dirk Krüger, Salvador Ortigueira, Harald Uhlig, Klaus Wälde, Mirko Wiederholt and seminar participants in Berlin, Florence and Oslo for helpful comments and I acknowledge the support of the Deutsche Forschungsgemeinschaft through the SFB 649 "Economic Risk". All errors are my sole responsibility.
} 


\section{Abstract}

I explore the implications of the lumpy labor adjustment as a propagation mechanism for aggregate dynamics. The model I use nests the basic RBC model with a staggeredjob-turnover in the spirit of Taylor (1980) and Calvo (1983). It extends this approach by introducing a Weibull-distributed labor adjustment process to capture increasing hazard rates and heterogeneous labor rigidity in the economy corroborated by the micro data. My principal findings are: uncertainty in the labor adjustment process induces firms to make precautionary labor adjustment (the front-loading effect), amplifying the volatility of labor demand, and that the heterogeneity in labor rigidity leads to aggregate persistence in labor and output. The key message conveyed by this model is that heterogeneity in labor rigidity matters for the aggregate dynamics, and hence includes the information of the distribution of agents enriching the propagation mechanism of the RBC model.

JEL Classification: E32; E24; C68

Keywords: Business cycles; Heterogeneous labor rigidity; Weibull distribution; Increasing hazard function 


\section{Introduction}

The standard RBC model has been extended in various directions to enhance its internal propagation mechanism. One string of the literature emphasizes the role played by the imperfect labor adjustment in propagating business cycles. For example, the search and matching model (Merz, 1995 and Andolfatto, 1996) generates persistence in labor dynamics by assuming matching frictions in the labor adjustment. The factor hoarding model (Burnside and Eichenbaum, 1996) assumes that extensive margins are predetermined, while the intensive margins can only be adjusted in a costly way; The habit formation model (Wen, 1998) emphasizes the role of the household's willingness to smooth the path of leisure; And the learning-by-doing model (Chang, Gomes, and Schorfheide, 2002) is motivated by the assumption that current labor input affects future output through a worker's skill accumulation. These models have one feature in common-they rely on introducing lagged labor into the aggregate dynamics in order to replicate persistence in output and employment. However, they have to face a trade-off between persistence and volatility of dynamics. Consequently, these models usually need to be strengthened by other mechanisms to account for the magnitude of the observed fluctuations. Wen (1998), for example, combined the habit formation in leisure with the increasing-return-to-scale technology, and Shimer (2003) and Hall (2003) raise volatility of unemployment by introducing wage rigidity.

In this paper, I pursue the implications of the micro lumpy labor adjustment with a novel approach and show it has the ability to reconcile both the persistence and the magnitude of business cycle fluctuations.

An increasing amount of empirical evidence has been accumulating, showing that labor demand at the firm level is lumpy and heterogeneous. Earlier evidence has been presented by Hamermesh (1989) and Caballero, Engel, and Haltiwanger (1997). Recently Varejão and Portugal (2006) find that large employment adjustments (larger than $10 \%$ of the plant's labor force) account for about $66 \%$ of the total job turnover, and on average around $75 \%$ of all observed Portuguese employers do not change employment over an entire quarter. When estimating parameters of the Weibull hazard function with the Portuguese employer survey data, they found that the shape parameter lies in the range between 1.174 and 1.309, indicating an increasing hazard function in the elapsed inactive time.

In theoretical work, $(\mathrm{S}, \mathrm{s})$ models are popular for addressing questions of aggregate effects 
in lumpy factor adjustments ${ }^{2}$, The earlier partial equilibrium $(\mathrm{S}, \mathrm{s})$ models of labor adjustment ${ }^{3}$ found that employment growth depends on the cross-sectional distribution of the employment deviation from the optimal target. However, recent general equilibrium $(\mathrm{S}, \mathrm{s})$ models disagree with significant effects of the micro-lumpiness on the aggregate dynamics and show that those effects disappear with changes in equilibrium prices. King and Thomas (2006) found that lumpy labor adjustments do not generate observationally different aggregate dynamics from a standard partial adjustment mode $\mathbb{4}^{4}$.

In this paper, instead of using the general equilibrium $(\mathrm{S}, \mathrm{s})$ model, I tackle this issue by adopting the modeling strategy originally proposed by Kiyotaki and Moore (1997)5. I first assume that a firm's labor adjustment obeys a staggered rule in the spirit of Fischer (1977), Taylor (1980) and Calvo (1983), and then I extend the baseline model to a more general case, in which I introduce a Weibull-distributed labor adjustment process to capture features of increasing hazard rates and heterogeneous labor rigidity corroborated by micro evidence. In fact, it extends the Poisson labor adjustment process that underlies the Calvo assumption to a non-constant-hazard adjustment model using the Weibull distribution. Serial studies by Hamermesh (e.g. Hamermesh, 1989, Hamermesh, 1993 and Hamermesh and Pfann, 1996) have shown that information about the distribution of sub-units is crucial to linking micro-level features with implications for macro behavior deduced by determining the correct mechanism for aggregation. Thus my model is an endeavor to illustrate how this mechanism works in propagating realistic business cycle fluctuations.

The principal findings are that uncertainty in the labor adjustment process increases employment volatility at firm's level and causes the lumpy fashion of factor adjustment. At the micro level, firm's labor demand exhibits the 'front-loading effect' and the 'tradeoff' effect, i.e. when a positive persistent technology shock occurs to the economy, firms hire more workers than they currently need to hedge the risk that they may not be able to re-optimize their labor input in the near future. The 'trade-off' effect sums up the fact that firms weigh the importance of the current shock and future shocks according to flexibility of the labor market. When the labor market is more rigid, firms put more weight on future shocks than the current ones, and vice verse. Numerical results show that both effects help amplify the volatility of labor dynamics on the micro level. On the aggregate level, however, the lumpy labor adjustment is neutralized by the aggregation

2 Caplin and Spulber (1987) was the early work applying the (S,s) approach to macro models.

3 See: e.g. Caballero and Engel (1993), Caballero, Engel, and Haltiwanger (1997)

${ }^{4}$ Similar results have been also found in the capital adjustment context. See, e.g., Veracierto (2002) and Thomas (2002)

${ }^{5}$ Sveen and Weinke (2005) used the same idea to study the lumpiness in investment in a New-Keynesian model. 
mechanism implied by the restrictive Calvo-style labor adjustment. To this end, I show that the aggregate labor demand equations derived from the Calvo-adjustment model and the quadratic-adjustment-cost model correspond to the same reduced form, and deep parameters have a one-to-one mapping of each other, so the aggregate dynamics generated by both models are virtually the same given comparable parameter values.

By contrast, when relaxing the Calvo-style assumption to an increasing-hazard-Weibull case, the model exhibits a quantitatively significant propagation mechanism with respect to both aggregate persistence and volatility. In particular, it can generate highly volatile aggregate employment as observed in the data. In addition, through the introduction of heterogeneous labor rigidity, persistence of labor dynamics are improved and lead to hump-shaped impulse responses. This improvement results from the aggregation mechanism underlying the Weibull distribution over heterogeneous labor vintages. In this model, the firm's optimal labor demands are disparately sticky across labor vintages. Combining this with the fact that the aggregate mechanism assigns a higher weight to the more rigid labor vintage, the Weibull adjustment model is able to account for highly persistent labor dynamics. In conclusion, heterogeneity of employment dynamics and the aggregation mechanism play a central role in propagating business cycles.

The remainder of the paper is organized as follows: Section 1 introduces the baseline model with a staggered employment adjustment at the firm's level ; In section 2, I show some analytical results to reveal the key mechanism underlying the model; Section 3 extends the basic model to the Weibull-adjustment model; and in section 4 I introduce the calibration of model parameters and present simulation results; Section 5 contains some concluding remarks.

\section{The Baseline Model}

In this section, I set up the baseline model in a standard RBC framework. The main feature of the basic model is to adopt the modeling strategy originally proposed by Kiyotaki and Moore (1997) to model the lumpy labor adjustment at the plant level and study its impact on the aggregate dynamics. Even though this modeling idea has existed for a long time and it is familiar to most researchers in macroeconomics, I introduce it here formally in the context of the statistical duration model, which also serves as the solid theoretical base for the extension I introduce in the next section. 


\section{Household}

There is a continuum of identical households, who are endowed with $K_{0}$ units of capital at $t=0$ and then with one additional unit for each subsequent period of time, which can be spent on either working or leisure. The infinitely-lived representative household chooses consumption, labor supply and investment to maximize the expected discounted utility:

$$
U=\max _{\left\{C_{t}, L_{t}, I_{t}\right\}} E_{0}\left\{\sum_{t=0}^{\infty} \beta^{t}\left(U\left(C_{t}\right)-V\left(L_{t}\right)\right)\right\} .
$$

The instantaneous utility $U($.$) and V($.$) are bounded, continuously differentiable, strictly$ increasing and strictly concave in consumption and leisure. I take the following function form for instantaneous utility:

$$
U\left(C_{t}\right)-V\left(L_{t}\right)=\frac{C_{t}^{1-\eta}}{1-\eta}-\chi \frac{L_{t}^{1+\phi}}{1+\phi}
$$

In each period, households receive wage income, rental payment for their capital stock and a lump-sum transfer of net profits resulting from firm ownership, which can be spent on consumption and investment in capital stocks. Due to the assumption of complete financial markets, all households can perfectly share their idiosyncratic income risk, so that they consume and invest the same amount. Consequently, the sequence of aggregate budget constraints is given by:

$$
C_{t}+I_{t} \leq W_{t} L_{t}+R_{t} K_{t}+T_{t}
$$

The capital stock evolves according to the following law of motion:

$$
K_{t+1}=(1-\delta) K_{t}+I_{t}
$$

Finally, I restrict the model so that no capital is left unused at the end of the life, and hence impose the transversality condition as follows:

$$
\lim _{T \rightarrow \infty} E_{0}\left[\prod_{t=0}^{T} R_{t, t+1}^{-1}\right] K_{T+1}=0,
$$


Based on this setup, the following first order conditions must hold in an equilibrium:

$$
\begin{gathered}
\chi L_{t}^{\phi} C_{t}^{\eta}=W_{t}, \\
1=E_{t}\left[\beta\left(\frac{C_{t+1}}{C_{t}}\right)^{-\eta}\left(r_{t+1}+1-\delta\right)\right],
\end{gathered}
$$

\section{Firms}

Firms in the economy operate in a rigid labor market, where some unspecified frictions cause a fixed ratio of firms not to adjust their labor input in each period. The labor market forms a common expectation of this ratio. In effect, the more rigid the labor market is, the lower the adjustment ratio is, as expected by agents in the market.

Further I assume that firms can access an instantaneous rental market for capital, which is supplied by households in any given period. This assumption is desirable because the firm's first order condition requires the capital and labor ratio to be identical in the entire economy ${ }^{6}$, the instantaneous capital market makes possible for those firms that can not change their employment to fulfill this requirement. The aggregate capital stock, however, is still predetermined by the household.

Firms use a decreasing-return-to-scale technology to produce output?

$$
y_{t}=Z_{t} l_{t}^{a} k_{t}^{b} \quad \text { and } \quad a+b<1
$$

$Z_{t}$ summarizes the aggregate productivity shock, which consists of a trend component $\bar{Z}_{t}$ and a realization of a stochastic process $z_{t}$. The trend component $\bar{Z}_{t}$ evolves at a constant growth rate $g$, while $z_{t}$ follows an $\mathrm{AR}(1)$ process in logs:

$$
Z_{t}=\bar{Z}_{t} z_{t}
$$

where $\quad z_{t}=z_{t-1}^{\varsigma} e^{v_{t}}, \quad$ and $\quad v_{t} \sim i . i . d . N\left(0 ; \sigma^{2}\right)$

\footnotetext{
${ }^{6}$ This is the case when the production function is constant-return-to-scale, however, when assuming decreasing-return-to-scale, as shown in equation(18), a power function of labor and capital depends only on the rental rate and aggregate shocks, hence it should be identical for all firms in the economy.

${ }^{7}$ The diseconomy of scale can be theoretically motivated in several ways. e.g. Howitt and McAfee (1988) emphasized the role of externalities, i.e. the marginal adjustment cost faced by a firm is positively related to the activity level already attained by its rivals.
} 
The decreasing-return-to-scale assumption enables me to show the lumpy effect at the plant level, but it also presents problems. The first problem is that firms earn profits using decreasing-return-to-scale production technology. Secondly, the smaller the firm is, the more efficient it becomes in the sense of profits per unit of production. Hence a firm has incentive to be small. In order to set a minimum size for the firm, I introduce a fixed cost of operation $(\iota)$, which is equal to the profits earned in the steady state. In a stochastic environment, all firms earn positive profits in some periods and negative profits in the other periods, and expect zero profit in the long run. Consequently, no entry and exit occurs in this economy and hence the number of firms is constant.

\section{Staggered Labor Adjustment and Distribution of Firms}

In this subsection, I formally introduce the staggered labor adjustment process in the context of the statistical duration model.

Here I consider a process in which the firm's employment adjustment occurs randomly over time. It turns out that under some basic assumptions with respect to independence and uniformity in time, this random process is governed by the Poisson process 8 . This assumption simplifies the real-world continuous factor adjustment decisions in terms of a sequence of generic trials that satisfy the following assumptions:

- Each trial has two possible outcomes, called adjustment and non-adjustment.

- The trials are memoryless, i.e. the outcome of one trial has no influence over the outcome of another trial.

- For every firm, the probability of adjusting is $1-\alpha$ and the probability of nonadjusting is $\alpha$.

Formally I define the labor adjustment process as a Bernoulli process as follows:

Definition: Given a probability space $(\Omega, P r)$ together with a random variable $X$ over the set $\{0,1\}$, so that for every $\omega \in \Omega, X_{i}(\omega)=1$ with probability $\alpha$ and $X_{i}(\omega)=0$ with probability $1-\alpha$, where $\Omega=$ adjusting, non-adjusting $\}$, a Bernoulli process is a sequence of integers $Z^{\omega}=\left\{n \in Z: X_{n}(\omega)=1\right\}$.

\footnotetext{
${ }^{8}$ In this paper, as I write the model in the discrete-time, the discretized adjustment process follows the Bernoulli trials process, which is the discrete version of the Poisson process.
} 
Given the factor adjustment process follows the Bernoulli process, the probability of receiving zero adjusting signal in an interval of $j$ periods is:

$$
\operatorname{Pr}(0)=\left(\begin{array}{l}
j \\
0
\end{array}\right)(1-\alpha)^{0} \alpha^{j}=\alpha^{j} \quad \text { for } j=0,1,2, \ldots
$$

And, the probability that a duration spell terminates at the period $j$ is

$$
\operatorname{Pr}(j)=(1-\alpha) \alpha^{j-1} \quad \text { for } j=0,1,2, \ldots
$$

The hazard function corresponding to the Bernoulli process is:

$$
H(j)=\frac{\theta(j)}{1-F(j)}=\frac{1-\alpha}{\alpha}
$$

The hazard function embeded in the Bernoulli distribution is constant. It implies that the probability of adjusting is independent of the period time elapsed.

The economy is populated by a continuum of firms, which is normalized to one. Due to the random labor adjustment process specified above, firms are differentiated by the amount of time that has elapsed since the last adjustment and hence by their stocks of labor force. I index firms by $j$, corresponding to the time-since-last-adjustment. I call them hereafter "labor vintages". Furthermore, given the complete financial market, adjusting firms choose a common target labor adjustment at each period. Firms in any labor vintage share an equal amount of employment, and hence the state of the economy can be summarized by the vintage index $j$ with the corresponding labor stock $\left(l_{j, t}\right)$.

The aggregate stock of labor can be summed up with respect to the distribution of firms over labor vintages, i.e. the aggregate labor is the weighted sum of all past optimal labor demands, and weights are equal to the probability density function over vintages $j$.

Define $\Theta=\{\theta(j)\}_{j=0}^{\infty}$ as the distribution of firm over labor vintages. It can be easily shown that $\theta(j)=(1-\alpha) \alpha^{j}$ for $j=0,1,2, . .{ }^{9}$

Finally aggregate labor is obtained by ${ }^{10}$ :

\footnotetext{
${ }^{9}$ Because, by assumption there is $1-\alpha$ fraction of firm in the group zero, and $\alpha$ percent of them goes to group one, this gives the density of group one to be $(1-\alpha) \alpha$. Similarly, $\alpha$ percent of untis in group one goes to group two, so the density of group two is $(1-\alpha) \alpha^{2}$, and so on.

10 Note that equation 18 implies that firms in the vintage $j$ group must also use same amount of capital. Thus the distribution of plants over labor is the same as over capital stocks. As a result, we can
} 


$$
L_{t}=\sum_{j=0}^{\infty} \theta(j) l_{j, t}=\sum_{j=0}^{\infty}(1-\alpha) \alpha^{j} l_{j, t}
$$

Since the fraction of firms that adjust their employment is randomly drawn across the population, it can be easily iterated to obtain the recursive law for aggregate employment.

$$
L_{t}=(1-\alpha) l_{0, t}+\alpha L_{t-1}
$$

or equivalently,

$$
\Delta L_{t}=L_{t}-L_{t-1}=(1-\alpha)\left(l_{0, t}-L_{t-1}\right)
$$

This equation reveals the partial adjustment nature of this model, that the actual job turnover is only a fraction of the optimal adjustment. The speed of adjustment depends on the extent of market rigidity $(1-\alpha)$. If no friction exists in the labor market $(\alpha=0)$, all firms re-optimize their labor by $l_{0, t}$, where this model is then reduced to the standard $\mathrm{RBC}$ case.

\section{Firm's optimization Problem}

In spite of heterogeneous nature of the problem, the firms' maximization problem can be written in a representative fashion: a typical firm maximizes the expected discounted real value of all future profits by choosing nonnegative values for current optimal labor $l_{0, t}$ and a sequence of optimal capital stocks $\left\{k_{j, t}\right\}_{j=0}^{\infty}$, subject to the information set $\Omega_{t}$ at the period $t$ taking the real wage $w_{t}$ and real rental rate $r_{t}$ as given.

$$
\max _{l_{0, t},\left\{k_{j, t}\right\}_{j=0}^{\infty}} V_{t}=\sum_{j=0}^{\infty} E_{t}\left\{\tilde{\beta}_{t, t+j} \alpha^{j}\left[F\left(l_{0, t}, k_{j, t}\right)-w_{t+j} l_{0, t}-r_{t+j} k_{j, t+j}\right] \mid \Omega_{t}\right\}
$$

where $\tilde{\beta}_{t, t+j}$ is the stochastic discount factor, which is defined according to equation (7).

aggregate capital in the same way.

$$
K_{t}=\sum_{j=0}^{\infty}(1-\alpha) \alpha^{j} k_{j, t}
$$


Since, at the steady state, all real variables except for labor grow at rate $g$ along the balanced growth path, I will work with detrended variables without changing the notions from now on.

First order conditions for the firm's optimization problem are:

$$
\begin{gathered}
r_{t}=f_{k}(j, t)=b z_{t} \frac{l_{j, t}^{a}}{k_{j, t}^{1-b}} \\
\sum_{j=0}^{\infty} \alpha^{j} E_{t}\left[\tilde{\beta}_{t, t+j}\left(a z_{t+j} l_{0, t}^{a-1} k_{j, t+j}^{b}-w_{t+j}\right)\right]=0
\end{gathered}
$$

Equation (18) shows that at any period some function of labor-capital-ratio has to be the same for all firms. This is the capital demand function given the rental rate and employment. Eqation (19) characterizes optimal labor demand of an adjusting firm at period $t$. Note that if I assume the production function is constant-return-to-scale, these two first order conditions can only pin down the ratio of labor and capital, and not the levels.

To reveal the model's implication for the optimal labor demand at the firm's level, I derive the firm's optimal employment demand by combining first order conditions and solving for the plant's optimal labor demand $l_{0, t}$ at period $t$ :

$$
l_{0, t}^{\frac{1-a-b}{1-b}}=\frac{a b^{b / 1-b} \sum_{j=0}^{\infty} \alpha^{j} E_{t}\left[\tilde{\beta}_{t, t+i} z_{t+j}^{1 / 1-b} / r_{t+j}^{b / 1-b}\right]}{\sum_{j=0}^{\infty} \alpha^{j} E_{t}\left[\tilde{\beta}_{t, t+i} w_{t+j}\right]}
$$

Equation 20 shows that, at the firm level, the optimal labor demand reacts to all future shocks and the equilibrium prices. In particular, it is increasing in all expected future shocks $z_{t+j}$ and decreasing in all expected future prices $w_{t+j}$ and $r_{t+j}$. In the partial equilibrium, where prices are constant, it is easy to see that a positive persistent shock will make the individual labor adjustment higher than that in the frictionless economy. Firms hire more labor than they currently need to hedge the risk they might not be able to re-optimize it in the near future and vice verse for the negative shocks. I call it the 'front-loading' effect of the labor demand under the uncertainty in the labor adjustment process. 


\section{Equilibrium}

Given an exogenous stochastic process for aggregate technology shocks and the common knowledge of the firms' distribution across vintage groups $\Theta$, I define the competitive equilibrium as a set of stochastic processes of endogenous variables $\left\{Y_{t}, C_{t}, L_{t}, l_{j, t}, k_{j, t}, I_{t}, K_{t}\right.$, $\left.w_{t}, r_{t}\right\}_{t=0}^{\infty}$ such that:

1. Given $K_{t}$ and the market prices $\left\{w_{t}, r_{t}\right\}_{t=0}^{\infty}$, the sequences $\left\{C_{t}^{s}, L_{t}^{s}, I_{t}^{s}\right\}_{t=0}^{\infty}{ }^{11}$ solve the representative household's maximization problem (1) subject to (2)-(5).

2. Given $\left\{w_{t}, r_{t}\right\}_{t=0}^{\infty},\left\{l_{j, t}, k_{j, t}\right\}_{t=0}^{\infty}$ solve the Firms' profits maximization problem (17) subject to production technology (8) and exogenous technology shock process (9).

3. Aggregate demands for employment $L_{t}^{d}$ and capital $K_{t}^{d}$ are determined by (14) and (13) respectively.

4. Markets clear: $L_{t}^{s}=L_{t}^{d}=L_{t}$ in labor market, $K_{t}^{s}=K_{t}^{d}=K_{t}$ in capital market and $C_{t}+I_{t}=Y_{t}$ in the goods market.

5. Finally, market's equilibrium determines the equilibrium real wage and rental rate $\left\{w_{t}, r_{t}\right\}_{t=0}^{\infty}$

\section{Analysis}

\section{Dynamic Labor Demand Equations}

To gain further intuition of the firm's behavior, I log-linearizing the FOCs (18) and (19) around the non-stochastic steady state ${ }^{12}$. In contrast to the other partial adjustment model, the Calvo-adjustment model implies different labor demand behaviors at different aggregation levels.

$$
\hat{l}_{0, t}=\alpha \beta E_{t}\left[\hat{l}_{0, t+1}\right]-\frac{b(1-\alpha \beta)}{1-a-b} \hat{r}_{t}-\frac{(1-b)(1-\alpha \beta)}{1-a-b} \hat{w}_{t}+\frac{1-\alpha \beta}{1-a-b} z_{t}
$$

Together with equation (15), the aggregate labor demand equation is obtained by:

$$
\alpha \beta \kappa E_{t}\left[\hat{l}_{t+1}\right]-\left(1+\alpha^{2} \beta\right) \kappa \hat{l}_{t}+\alpha \kappa \hat{l}_{t-1}-\frac{b \bar{R}}{\bar{r}} \hat{R}_{t}-(1-b) \hat{w}_{t}+z_{t}=0
$$

\footnotetext{
11 Here, superscript $s$ denotes "supply"; Similar notation $d$ for "demand"

12 Variables with hat are denoted as log deviation from the non-stochastic steady state, such as $\hat{x}_{t}=$ $\log X_{t}-\log \bar{X}$; and the derivation is shown in a technical appendix, which is available upon request.
} 
where $\kappa=\frac{(1-a-b)}{(1-\alpha)(1-\alpha \beta)}$

Note that, using constant-return-to-scale technology, the firm's problem only solves the optimal ratio of capital and labor. To avoid this problem, I need some degrees of decreasingreturn-to-scale.

Equation (21) reveals that at firm's level optimal adjustment is forward-looking and a trade-off exists between the weights assigned to the current shock and future shocks. When $\alpha$ is large, firms put more weight on future shocks than on current shocks. Because the labor market is more rigid in this case, firms expect that they may not re-optimize their labor forces in the near future. I name it the 'trade-off' effect.

The aggregate labor demand 22 exhibits more complex dynamics, which are not only dependent on the forward-looking component, but also on the lagged labor. The labor market rigidity parameter $\alpha$ affects the dynamic property of labor demand, while the capital share $b$ has influence on the elasticity of labor demand with respect to prices. In particular, when the capital share rises, interest rate elasticity increases, while wage elasticity decreases.

\section{Equivalence of the Partial Adjustment Models}

The quadratic-adjustment-cost model has lost footing in macroeconomic literature because economists have grown disenchanted with its smoothing and synchronous implication relating to the firm-level factor adjustment. As discussed in the introduction, mounting micro evidence shows that firms adjust their labor in a discrete and asynchronous fashion. Despite this fact, the quadratic adjustment cost model has been used widely in theoretical and empirical work. Because they are easily solved and produce aggregate equations in a form suitable for estimation. By contrast, as I have shown in the equation (20), the Calvo-adjustment model can capture lumpy and asynchronous features in firm's labor adjustment, while aggregate labor demand in this model is characterized by a smoothing $\operatorname{AR}(2)$ dynamic process (see: equation 22). The key question addressed in this subsection is whether the quadratic-adjustment-cost model is equivalent to the Calvoadjustment model concerning the aggregate dynamics. If this is true, it can be treated as a reduced form model and is still valid in the empirical work using aggregate data.

In appendix $(\mathrm{A})$, I derive the aggregate labor demand equation from a textbook quadraticadjustment-cost model(See e.g. Hamermesh (1993)). As Rotemberg (1987) has shown that the equivalence between the Calvo model and the quadratic cost model in the price 
adjustment context, it can also be shown analytically that aggregate labor demand equations derived from both models conform to the same reduced form. In addition, the deep parameters of the two models have a one-to-one mapping of each other.

Comparing the equation (35) to the dynamic labor demand equation which I derived from the Calvo-adjustment model, I find that these two equations can be put into the following reduced form equation, so that the aggregate data alone can not differentiate between them.

$$
\varphi_{1} E_{t}\left[\hat{l}_{t+1}\right]+\varphi_{2} \hat{l}_{t}+\varphi_{3} \hat{l}_{t-1}+\varphi_{4} \hat{R}_{t}+\varphi_{5} \hat{w}_{t}+z_{t}=0
$$

In addition, if I set $\alpha \kappa=\gamma$, For example, the correspondence among parameters in both models is expressed by equation (23). Then the Calvo-adjustment model is equivalent to the quadratic-adjustment-cost model with respect to the aggregation relations and they consequently generate the exact same aggregate dynamics, given that all other aspects of both models are equal.

$$
\frac{d \bar{n}}{\bar{w}}=\frac{\alpha(1-a-b)}{(1-\alpha)(1-\alpha \beta)(1-b)}
$$

Note that both parameters $d$ and $\alpha$ govern the rigidity of the labor adjustment process in both models and this equation gives the exact mapping between these two rigidity parameters.

\section{Extension}

In this section, I extend the baseline model to a more general case in which the labor adjustment process is characterized by an increasing hazard function. As shown in the previous section, the Poisson process underlying the Calvo assumption implies a constant hazard function, which is strongly rejected by the micro data. To avoid this weakness, I apply the Weibull distribution ${ }^{13}$ to model the firm's labor adjustment process. The Weibull distribution is frequently used in statistical analysis of duration phenomena because of its flexibility, especially with respect to the hazard function that may increase or decrease accordingly. In fact, it enables the incorporation of a wide range of hazard functions by using various values of the shape parameter 14 . By modeling the labor adjustment

\footnotetext{
13 For detailed discussion on Weibull distribution, see technical appendix $B$

14 Any value of the shape parameter that is greater than one corresponds to an increasing hazard function, while values ranged between zero and one lead to a decreasing hazard function. By setting the shape
} 
process with a Weibull distribution, I can calibrate it by referring to estimation of the empirical hazard function based on the micro data. In this model, according to evidence provided by Varejão and Portugal (2006), I assume the labor adjustment process follows a Weibull distribution with an increasing hazard in terms of time-since-last-adjustment. In fact, it has important implications for the labor adjustment process. Thanks to the non-constant hazard rate, adjustment probabilities across labor vintages $j$ vary in this model. The longer a firm remains inactive, the more likely it adjusts its labor in the current period. As a result, heterogeneous labor-rigidity sectors emerge naturally from the underlying labor adjustment process, and as shown later, it plays a crucial role in propagating aggregate persistence.

\section{The Weibull-adjustment Model}

To integrate the Weibull-labor-adjustment into the RBC framework, I only have to modify the firm's problem, while keeping the household's optimal conditions (6) and (7) as we have in the baseline model.

I consider an economy with a continuum of perfectly competitive firms, which are differentiated with respect to the time elapsed since their last labor adjustment, indexed by $j \in\{0, \infty\}$. The distribution of firms across vintage groups is summarized by the density function of the Weibull distribution, $\Theta(j)$. Due to the increasing hazard rate, a firm's labor force found in different vintage groups has different survival rates $\alpha_{j}$ (the probability of not adjusting), which is decreasing in $j$.

In a given labor vintage $j$, when resetting its labor $l_{j, t}^{*}$ at time $\mathrm{t}$, a firm knows the adjusting probability for the current period and uses it to form the expectations of all future adjustment rates ${ }^{15}$. The firm chooses an optimal labor adjustment to maximize:

$$
\max _{l_{j, t}^{*},\left\{k_{j, t+i}\right\}_{i=0}^{\infty}} V_{t}=\sum_{i=0}^{\infty}\left(\alpha_{j}\right)^{i} E_{t}\left\{\tilde{\beta}_{t, t+i}\left[f\left(l_{j, t}^{*}, k_{j, t+i}\right)-w_{t+i} l_{j, t}^{*}-r_{t+i} k_{j, t+i}\right]\right\}
$$

The first order necessary condition gives us the optimal labor adjustment in the vintage

parameter to be one, we can retrieve the Poisson process from the Weibull distribution.

15 This amounts to assuming that firms do not know the true statistical adjustment process in the whole economy. They only use current experience to form future expectation on the adjustment rate. In the previous version of this paper, I also simulate the results from a model, in which agents know the true Weibull distribution of the labor adjustment process. However, the main results are not affected by this modification. 
group $j$ :

$$
l_{j, t}^{*} \frac{\sum^{\frac{1-a-b}{1-b}}\left(\alpha_{j}\right)^{i} E_{t}\left[\tilde{\beta}_{t, t+i} z_{t+i}^{1 / 1-b} / r_{t+i}^{b / 1-b}\right]}{\sum_{i=0}^{\infty}\left(\alpha_{j}\right)^{i} E_{t}\left[\tilde{\beta}_{t, t+i} w_{t+i}\right]},
$$

Equation (24) reveals the same basic message about the optimal labor demand as in the baseline model, except that the firm's optimal labor demand is now different across labor vintages. Because each labor vintage has a different survival rate $\alpha_{j}$, the younger labor vintages expect a larger non-adjusting rate and are hence more sensitive to the future economic conditions than those in the older labor vintages.

To aggregate the labor demand, I use a two-stage aggregation scheme. First I define the ex ante vintage labor demand as $L_{j, t}$, which is represented by:

$$
L_{j, t}=\left(1-\alpha_{j}\right) l_{j, t}^{*}+\alpha_{j} L_{j, t-1}
$$

Note that this is the sum of labor demand in a labor vintage before reshuffling firms into the new vintage groups. Then at the second stage, I aggregate the vintage labor demand into the aggregate labor demand.

$$
L_{t}=\int_{0}^{\infty} \Theta(j) L_{j, t} d j
$$

\section{Labor Demand Equations}

To explore the effect of the increasing-hazard labor adjustment process on the aggregate dynamics, I log-linearize the labor demand equation and the aggregate equations.

First I log-linearize equation(24) for the labor demand at the firm's leve ${ }^{16}$.

$$
\hat{l}_{j, t}^{*}=\alpha_{j} \beta E_{t}\left[\hat{l}_{j, t+1}^{*}\right]-\frac{b\left(1-\alpha_{j} \beta\right)}{1-a-b} \hat{r}_{t}-\frac{(1-b)\left(1-\alpha_{j} \beta\right)}{1-a-b} \hat{w}_{t}+\frac{1-\alpha_{j} \beta}{1-a-b} z_{t}
$$

As in the baseline model, the optimal labor adjustment is increasing in all expected future shocks $z_{t+j}$ and decreasing in all expected future prices $w_{t+j}$ and $r_{t+j}$, and thus the 'frontloading' effect is also at work here. In addition, because the non-adjustment rates $\alpha_{j}$ are disparate across vintages due to the 'trade-off' effect, the optimal labor adjustments $\left(l_{j, t}^{*}\right)$ respond differently to the aggregate shock. Because of the higher survival rate $\alpha_{j}$, for

\footnotetext{
${ }^{16}$ The derivation of this equation is available from the author upon request.
} 
firms in a younger vintage, they put more weights on future shocks than on the current shock. By contrast, firms in an older vintage react more to the current shock, and less to the future shocks. As a result, the optimal labor demand in the younger labor vintage is more persistent than those in the older labor vintage, and hence heterogeneity in labor rigidity emerges naturally from the underlying labor adjustment process in this economy. Together with equation (25), the vintage labor demand equation is obtained by:

$$
\alpha_{j} \beta E_{t}\left[\hat{l}_{j, t+1}\right]-\left(1+\alpha_{j}^{2} \beta\right) \hat{l}_{j, t}+\alpha_{j} \hat{l}_{j, t-1}-b \kappa \hat{r}_{t}-(1-b) \kappa \hat{w}_{t}+\kappa z_{t}=0
$$

where $\kappa=\frac{\left(1-\alpha_{j}\right)\left(1-\alpha_{j} \beta\right)}{(1-a-b)}$

At last, I can derive the aggregate labor demand from equation 28):

$$
\hat{l}_{t}=\int_{0}^{\infty} \Theta(j) \hat{l}_{j, t} d j
$$

Equation (29) reveals that the aggregation mechanism plays an important role in forming aggregate dynamics. Given the heterogeneous nature of the economy, employment dynamics in different labor vintages are not equally persistent, and their contributions to the aggregate dynamics depend on their weights associated. In the next section, I show with numerical results that the Weibull-adjustment model can account for both persistence and volatility of aggregate labor with a realistic set of parameter values.

\section{Calibration and Simulation Results}

In this paper, I investigate quantitative significance of lumpy labor adjustment as a propagation mechanism for business cycles. In order to address this question properly, I follow the tradition of RBC literature and calibrate my optimal growth model such that it is consistent with long-run growth facts in U.S. data, and then study its short-run dynamics by investigating the statistical properties of simulated time series and impulse responses functions. In the following sections, I address the calibration method for this model and then present the quantitative results and impulse response functions.

\section{Calibration}

For most parameters in the model, I take the standard values in the RBC literature. As for special parameters of the Weibull distribution, I refer to evidence of empirical studies 
using micro employment data.

For the quarterly discount rate $\beta$ I use 0.9902 to reflect that the real rate of interest in the U.S. economy is around $4 \%$ per annum. The depreciation rate $\delta$ is 0.025 , indicating an annual rate of $10 \%$. Given these two values, I select the capital share $b$ to be 0.329 to match the average capital-output ratio of 2.353 (Thomas and Khan, 2004), and the labor share of output $a$ is set to be 0.58 , which is consistent with direct estimates for the U.S. economy. (King, Plosser, and Rebelo, 1988).

As to the preference parameters, I choose $\phi=0.25$ implying that the average household allocates one quarter of the time to productive activities (Benhabib and Farmer, 1992), and $\sigma=1$, which gives rise to a log utility function for consumption.

The labor adjustment parameter is calibrated according to empirical work estimating the hazard function using aggregate net flow data. Caballero and Engel (1993) used U.S. manufacturing employment and job flow data (1972:1-1986:4) to estimate the constant hazard function. Their results suggest that on average, $22.9 \%$ of firms in the U.S. adjust their employment per quarter. As a result, I choose 0.77 as the value for $\alpha$ in the baseline model, which implies that the mean duration of employment is 4.35 quarters.

The Weibull parameters are set as follows: I set the shape parameter $\tau$ to be 1.2, implying an increasing hazard function. This value is based on Varejão and Portugal (2006), which estimated the Weibull duration model using survey data of Portuguese employers, and found the shape parameter is in the range between 1.174 to 1.309. ${ }^{17}$ To calibrate the scale parameter $\lambda$, I apply equation (39) to calculate the value for $\lambda$ such that it implies the same average duration of employment as in the Calvo-adjustment model. As a result, the characteristic life of the Weibull distribution is equal to 1.38 quarters, given $\tau=1.2$ and the average duration of 4.35 quarters.

Finally, I select the values of $\varsigma$ and $\sigma_{\epsilon}$ for aggregate technology shocks. I choose $\varsigma=0.95$ and a standard deviation of 0.007 , which are estimated parameters of Solow residuals that are commonly used in the RBC literature (King and Rebelo, 2000) 18 , The summary of calibration values are listed in Table(2):

\footnotetext{
${ }^{17}$ sensitivity analysis shows that my main result is not sensible to the value of $\tau$, so far it is greater than one.

18 Veracierto (2002) found the standard deviation of shocks should be smaller due to the decreasing return to scale assumption. He chose 0.0063 given his parameter values of labor and capital shares. However, since we are interested in the relative volatilities between variables to output, the scale of the standard deviation is not very important.
} 


\section{Numerical Results}

To evaluate the quantitative performance of the Weibull-adjustment model, I apply the log-linear approximation method of King, Plosser, and Rebelo (1988), which produces linear decision rules depending on the state variables, and then solve the rational expectation equilibrium by using the standard algorithm 19 .

In table (3)-(5), I report the second moments of U.S. data and those generated by the theoretical models. In all cases, the moments are for HP-filtered time series. For each of these models, three sets of statistics are reported: first, absolute and relative standard deviation; second, contemporaneous correlation coefficients relative to output; and third, the cross correlations with respect to output.

With the calibration values presented above, both theoretical models can replicate the general pattern of aggregate dynamics in the data. For example, the investment is about 3 times more volatile than output, while capital and consumption are less volatile than output. Moreover, as for persistence of dynamics, Cogley and Nason (1995) has shown that the standard RBC models fail to account for the observed positive serial correlation in the ooutput growth rate. By contrast, Calvo and Weibull-adjustment model enhance persistence of labor and output. As seen in the tables, both models can remarkably replicate autocorrelations for labor measures in the data and a slightly weaker persistence for output.

\begin{tabular}{l|c|cccc}
\hline \hline Labor Input & Relative & \multicolumn{4}{|c}{ Cross } \\
\cline { 1 - 5 } & S.D. & -3 & -2 & -1 & 0 \\
\hline U.S. data(Hours) & 0.98 & 0.38 & 0.54 & 0.78 & 0.92 \\
U.S. data(Employment) & 0.82 & 0.22 & 0.47 & 0.72 & 0.89 \\
\hline Calvo model & 0.49 & 0.34 & 0.47 & 0.71 & 0.95 \\
Weibull model & 1.01 & 0.32 & 0.53 & 0.76 & 0.99 \\
\hline
\end{tabular}

Table 1: Comparison of results of labor input

The key difference between the performance of the lumpy-adjustment models lies in the aggregate labor. Like other partial adjustment models, the Calvo-adjustment model has to face a trade off between volatility and persistence. As seen in table (1), it can account for only about half of the volatility of the labor observed in the data. By contrast, the Weibull-adjustment model generates a high level of volatility in the aggregate labor as in

${ }^{19}$ See, for example, Blanchard and Kahn 1980 ) and Uhlig (2001) 
the given data.
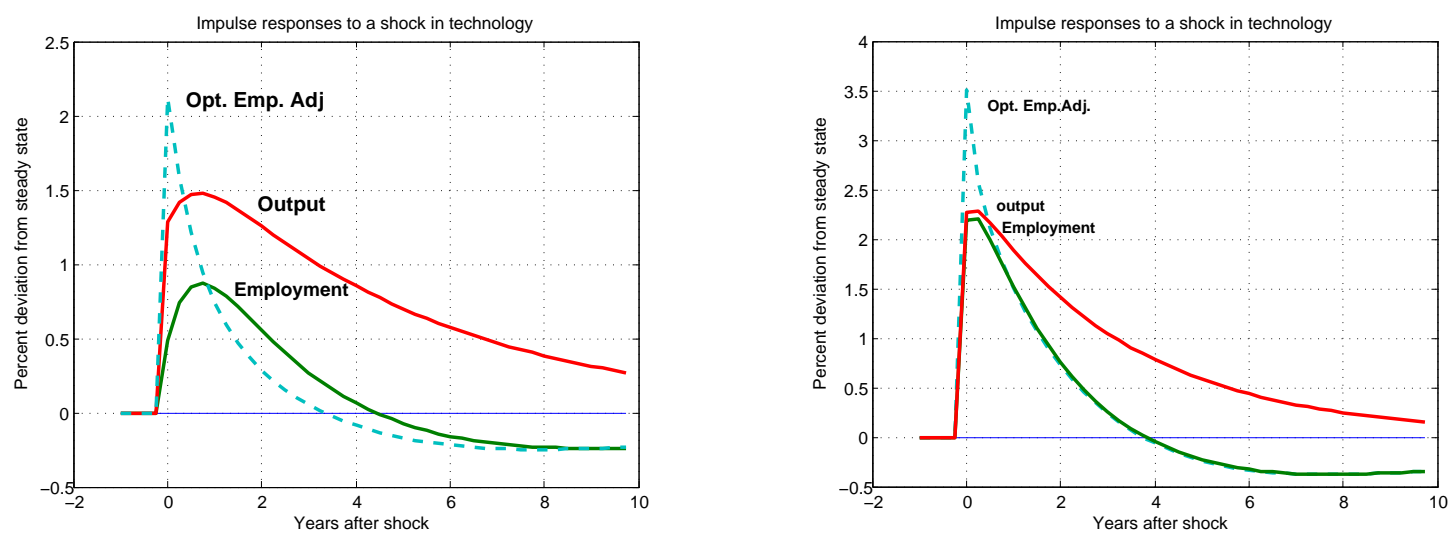

Figure 1: Impulse Responses of the Calvo model (left) and the Weibull model (right)

Figure(1) depicts the impulse response functions of labor and output to the aggregate technology shock. We can observe that both lumpy adjustment models can replicate humped-shaped impulse responses for aggregate labor and output. As for the volatility, the Weibull model generates much stronger responses (almost double in size) than the Calvo model in the absolute scale, and the relative scale of impulse responses between labor and output confirms the result we got in the simulation tables. I would thus argue that heterogeneity in the economy also has an important implication for the magnitude of business cycles. Even though the 'front-loading' effect makes individual firm's labor adjustment more volatile in the Calvo-adjustment model, the 'trade-off' effect coupled with heterogeneity in labor rigidity helps the Weibull model enhance the response even further.

Last but not least, these figures also illustrate the different patterns in response to the individual firm's employment and to the aggregate labor. In particular, the impulse response of aggregate labor is humped-shaped (solid line), while labor input at the firm's level reacts to the shock (dashed line) immediately and by a large amount. These results show that my theoretical model is able to replicate features observed in the labor adjustment data: i.e. At the micro level, labor adjustment exhibits a lumpy pattern in response to shocks; while, at the aggregate level, employment reacts smoothly and with some delay back to the steady state.

In table(1), it presents that the Weibull-adjustment model enables me to account for even higher persistent dynamics in aggregate hours. Because of its unique mechanism of aggregating heterogeneous labor rigidity, the Weibull model bring persistence of aggregate labor very close to the level observed in total hours in the U.S. data. 


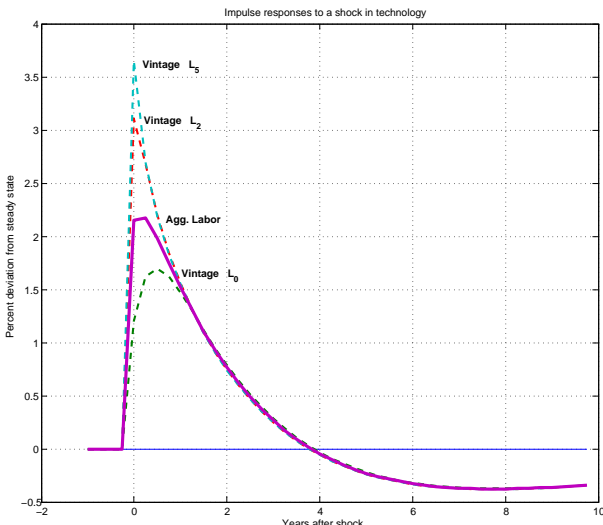

Figure 2: Impulse responses of labor in different aggregate levels

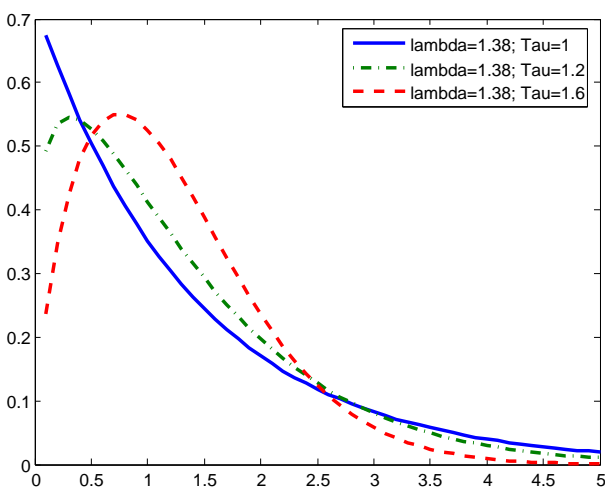

Figure 3: The Weibull distributions

To manifest the driving forces underlying this outcome, I present the impulse response functions of aggregate labor along with the decomposed vintage labor in figure (2). We see that aggregate labor (the solid thick line) is a combination of the sectoral labor from different vintages (Dashed lines). IRFs of different vintage labor show that they vary from the persistent early labor vintages (e.g. "Vintage $L_{0}$ ", the green dash line) to the brisk older labor vintages (e.g. "Vintage $L_{5}$ " the light blue dash line). From this result, we know that persistence of vintage labor decreases in $j$ (at least in the first two years). Recalling the aggregate labor demand equation (29), we know that aggregate labor is a weighted average of vintage labor demands, where the weights correspond to the probability density function of the Weibull distribution.

$$
\hat{l}_{t}=\int_{0}^{\infty} \Theta(j) \hat{l}_{j, t} d j
$$

Given the increasing hazard function, the aggregate mechanism assigns a higher weight to a younger labor vintage (see figure 3), which is more rigid than the older ones. This explains why the Weibull adjustment model helps to enhance persistence of labor dynamics.

\section{Concluding Remarks}

In this paper general equilibrium is generated in markets where the household's consumptionleisure choice meets the firm's factor demand decision under a staggered labor adjustment process. I model the staggered labor adjustment through a novel way, namely, applying the statistical duration analysis to extend the well-established time-dependent adjust- 
ment scheme in the spirit of Fischer (1977), Taylor (1980) and Calvo (1983) in a DSGE framework. Using the increasing-hazard Weibull distribution, the model generates heterogeneous labor vintages, which are different not only in the time of adjustment, but also regarding volatility and persistence of dynamics.

The key message conveyed in this paper is that uncertainty in the labor adjustment process induces firms to make precautionary labor adjustments, and firms weigh the importance of the current shock and future shocks with respect to flexibility in the labor market. I call these mechanisms the 'front-loading' effect and the 'trade-off' effect respectively, which amplify volatility of labor dynamics. In addition, heterogeneity of employment dynamics and the aggregation mechanism play a central role in propagating business cycles as well. Firm's optimal labor demands are differently persistent across labor vintages. Thanks to its aggregate mechanism assigning higher weights to more rigid labor vintages, the Weibull adjustment model is able to account for persistence in the labor dynamics.

In conclusion, given the heterogeneous nature of the economy, the representative-agent model tends to understate the impact of higher volatility and/or persistent sector in the economy on the aggregate variables. 


\section{A. Equivalence of the Partial Adjustment Models}

I first derive the aggregate labor demand equation from a textbook quadratic-adjustmentcost model(See e.g. Hamermesh (1993)).

In this economy, each firm is assumed to maximize the expected discounted real value of all future profits by choosing nonnegative values for optimal sequence of labors $l_{t+i}$ and optimal sequence of capital stocks $k_{t+i}$, subject to the quadratic labor adjustment costs.

The objective function of firm is:

$$
\max _{l_{t+i}, k_{t+i}} V_{t}=\sum_{i=0}^{\infty} E_{t}\left\{\tilde{\beta}_{t+i}\left[F\left(l_{t+i}, k_{t+i}\right)-w_{t+i} l_{t+i}-r_{t+i} k_{t+i}-\frac{d}{2}\left(l_{t+i}-l_{t+i-1}\right)^{2}\right]\right\}
$$

where $d$ is denoted as the adjustment cost parameter.

subject to

$$
y_{t}=Z_{t} l_{t}^{a} k_{t}^{b}
$$

and the total productivity shock $Z_{t}$ and the household's problem are the same as in the Calvo adjustment model.

The first order conditions are:

$$
\begin{gathered}
r_{t+i}=F_{K}(t+i)=b Z_{t+i} \frac{l_{t+i}^{a}}{k_{t+i}^{1-b}} \\
\tilde{\beta}_{t+i}\left[F_{L}(t+i)-w_{t+i}-d\left(l_{t+i}-l_{t+i-1}\right)\right]+E_{t}\left[\tilde{\beta}_{t+i+1} d\left(l_{t+i}-l_{t+i-1}\right)\right]=0
\end{gathered}
$$

It follows:

$$
a Z_{t+i} l_{t+i}^{a-1} k_{t+i}^{b}-w_{t+i}+\beta d l_{t+i+1}-d(1+\beta) l_{t+i}+d l_{t+i-1}=0
$$

If I log-linearize these FOCs around the steady state, I get the following dynamic labor demand equation:

$$
\gamma \beta E_{t}\left[\hat{l}_{t+1}\right]-[(1-a-b)+\gamma(1+\beta)] \hat{l}_{t}+\gamma \hat{l}_{t-1}-\frac{b \bar{R}}{\bar{r}} \hat{R}_{t}-(1-b) \hat{w}_{t}+z_{t}=0
$$

Where I denote $\gamma=\frac{d \bar{n}}{\bar{w}}(1-b)$. 


\section{Equivalence}

Comparing the equation (35) to the dynamic labor demand equation which I derived from the Calvo-adjustment model, I find that these two equations can be put into the following reduced form equation, so that the aggregate data alone can not differentiate them.

$$
\varphi_{1} E_{t}\left[\hat{l}_{t+1}\right]+\varphi_{2} \hat{l}_{t}+\varphi_{3} \hat{l}_{t-1}+\varphi_{4} \hat{R}_{t}+\varphi_{5} \hat{w}_{t}+z_{t}=0
$$

In addition, if I set $\alpha \kappa=\gamma$, i.e. the correspondence among parameters in both models follows the expression (23), then the Calvo-adjustment model is equivalent to the quadratic adjustment cost model, and hence they generate the exact same aggregate dynamics, given that all other aspects of both models are equal.

$$
\frac{d \bar{n}}{\bar{w}}=\frac{\alpha(1-a-b)}{(1-\alpha)(1-\alpha \beta)(1-b)}
$$




\section{B. Weibull Distribution and Aggregation}

\section{B.1. Weibull Distribution}

The PDF of Weibull distribution is given by the following expression:

$$
\operatorname{Pr}(j)=\frac{\tau}{\lambda}\left(\frac{j}{\lambda}\right)^{\tau-1} \exp \left(-\left(\frac{j}{\lambda}\right)^{\tau}\right)
$$

and the cumulative probability function is:

$$
F(j)=1-\exp \left(-\left(\frac{j}{\lambda}\right)^{\tau}\right)
$$

The parameters that characterize the Weibull distribution are the scale parameter $\lambda$ and the shape parameter $\tau$. The shape parameter determines the shape of the Weibull's pdf function, e.g. when $\tau=1$, it reduces to an exponential case; while $\tau=3.4$, the Weibull amounts to the normal distribution. The scale parameter defines the characteristic life of the random process that amounts to the time, at which $63.2 \%$ of the firm will adjust their labor. This can be seen with the evaluation of the cdf function of the Weibull distribution at $j$ equaling the scale parameter $\lambda$. Then we have, $F(\lambda)=1-e^{(-1)}=0.632$.

Note that it relates to the mean duration $\bar{j}$ according to the following equation:

$$
\bar{j}=\frac{1}{\bar{\alpha}}=\lambda \Gamma\left(\frac{1}{\tau}+1\right)
$$

where $\Gamma()$ is the Gamma function.

It follows that the hazard function of Weibull distribution is:

$$
H(j)=\frac{\tau}{\lambda}\left(\frac{j}{\lambda}\right)^{\tau-1}
$$

Note that this hazard is constant when the shape parameter $\tau$ equals one, and increasing when $\tau$ is greater than one. 


\section{Equations of the Weibull-adjustment model}

- Steady State Equations:

$$
\begin{aligned}
\bar{L} & =\frac{a[1-\beta(1-\delta)]}{\chi[1-\beta(1-\delta)-\delta \beta b]} \\
\bar{Y} / \bar{K} & =\frac{1-\beta(1-\delta)}{b \beta} \\
\bar{K}^{1-b} & =\frac{\bar{Z} \bar{K}}{\bar{Y}} \bar{L}^{a} \\
\bar{C} / \bar{K} & =\frac{1-\beta(1-\delta)-\delta \beta b}{b \beta} \\
\bar{W} & =\chi \bar{C} \\
\bar{R} & =\frac{1}{\beta} \\
\bar{I} & =\delta \bar{K}
\end{aligned}
$$

- Log-linearized Equations:

$$
\begin{aligned}
\hat{l}_{j, t}^{*} & =\alpha_{j} \beta E_{t}\left[\hat{l}_{j, t+1}^{*}\right]-\frac{b\left(1-\alpha_{j} \beta\right)}{1-a-b} \hat{r}_{t}-\frac{(1-b)\left(1-\alpha_{j} \beta\right)}{1-a-b} \hat{w}_{t}+\frac{\left(1-\alpha_{j} \beta\right)}{1-a-b} z_{t} \\
\hat{l}_{j, t} & =\left(1-\alpha_{j}\right) \hat{l}_{j, t}^{*}+\alpha \hat{l}_{j, t-1} \\
\hat{l}_{t} & =\int_{0}^{\infty} \Theta(j) \hat{l}_{j, t} d j \\
\hat{w}_{t} & =\phi \hat{l}_{t}+\eta \hat{c}_{t} \\
\eta \hat{c}_{t} & =E_{t}\left[\eta \hat{c}_{t+1}-\hat{R}_{t+1}\right] \\
\bar{R} \hat{R}_{t} & =\bar{r} \hat{y}_{t}-\bar{r} \hat{k}_{t} \\
\hat{y}_{t} & =z_{t}+a \hat{l}_{t}+b \hat{k}_{t} \\
\hat{k}_{t+1} & =\delta \hat{i}_{t}+(1-\delta) \hat{k}_{t} \\
\delta \hat{i}_{t} & =\bar{Y} / \bar{K} \hat{y}_{t}-\bar{C} / \bar{K} \hat{c}_{t} \\
z_{t+1} & =\varsigma z_{t}+v_{t}
\end{aligned}
$$




\section{References}

Andolfatto, D. (1996): "Business Cycles and Labor-Market Search," American Economic Review, 86(1), 112-32.

Benhabib, J., and R. E. Farmer (1992): "Indeterminacy and Increasing Returns," Ucla economics working papers, UCLA Department of Economics.

Blanchard, O. J., and C. M. Kahn (1980): "The Solution of Linear Difference Models under Rational Expectations," Econometrica, 48(5), 1305-11.

Burnside, C., and M. Eichenbaum (1996): "Factor-Hoarding and the Propagation of Business-Cycle Shocks," American Economic Review, 86(5), 1154-74.

Caballero, R. J., and E. M. Engel (1993): "Microeconomic Adjustment Hazards and Aggregate Dynamics," The Quarterly Journal of Economics, 108(2), 359-83.

Caballero, R. J., E. M. Engel, and J. Haltiwanger (1997): "Aggregate Employment Dynamics: Building from Microeconomic Evidence," American Economic Review, $87(1), 115-37$.

Calvo, G. (1983): "Staggered Prices in a Utility Maximizing Framework," Journal of Monetary Economics, 12, 383-398.

Caplin, A. S., And D. F. Spulber (1987): "Menu Costs and the Neutrality of Money," The Quarterly Journal of Economics, 102(4), 703-25.

Chang, Y., J. F. Gomes, and F. Schorfheide (2002): "Learning-by-Doing as a Propagation Mechanism," American Economic Review, 92(5), 1498-1520.

Cogley, T., And J. M. NAson (1995): "Output Dynamics in Real-Business-Cycle Models," American Economic Review, 85(3), 492-511.

Cooley, T. F. (1995): Frontiers of Business Cycle Research. Princeton University Press.

Fischer, S. (1977): "Long-Term Contracts, Rational Expectations, and the Optimal Money Supply Rule," Journal of Political Economy, 85(1), 191-205.

Hall, R. E. (2003): "Wage Determination and Employment Fluctuations," Nber working papers, National Bureau of Economic Research, Inc.

Hamermesh, D. S. (1989): "Labor Demand and the Structure of Adjustment Costs," American Economic Review, 79(4), 674-89. 
Hamermesh, D. S. (1993): Labor Demand. Princeton University Press.

Hamermesh, D. S., and G. A. Pfann (1996): "Adjustment Costs in Factor Demand," Cepr discussion papers, C.E.P.R. Discussion Papers.

Howitt, P., And R. P. McAfee (1988): "Stability of Equilibria with Externalities," The Quarterly Journal of Economics, 103(2), 261-77.

King, R. G., C. I. Plosser, and S. Rebelo (1988): "Production, Growth and Business Cycles: The Basic Neoclassical Model," Journal Monetary Economics, 21(2/3), $195-232$.

King, R. G., And S. T. Rebelo (2000): "Resuscitating Real Business Cycles," Nber working papers, National Bureau of Economic Research, Inc.

King, R. G., And J. K. Thomas (2006): "Partial Adjustment Without Apology," International Economic Review, 47(3), 779-809.

Kiyotaki, N., And J. Moore (1997): "Credit Cycles," Journal of Political Economy, $105(2), 211-48$.

Merz, M. (1995): "Search in the labor market and the real business cycle," Journal of Monetary Economics, 36(2), 269-300.

RotemberG, J. (1987): "The New Keynesian Microfoundations," NBER Macroeconomics Annual, December(2), 69-104.

Shimer, R. (2003): "The Cyclical Behavior of Equilibrium Unemployment and Vacancies: Evidence and Theory," Nber working papers, National Bureau of Economic Research, Inc.

Sveen, T., And L. Weinke (2005): "Is Lumpy Investment really Irrelevant for the Business Cycle?," Economics Working Papers 869, Department of Economics and Business, Universitat Pompeu Fabra, available at http://ideas.repec.org/p/upf/upfgen/869.html.

TAYlor, J. B. (1980): "Aggregate Dynamics and Staggered Contracts," Journal of Political Economy, 88(1), 1-23.

Thomas, J. K. (2002): "Is lumpy investment relevant for the business cycle?," Discussion paper.

Thomas, J. K., And A. Khan (2004): "Idiosyncratic shocks and the role of nonconvexities in plant and aggregate investment dynamics," Discussion paper. 
Uhlig, H. (2001): "A Toolkit for Analyzing Nonlinear Dynamic Stochastic Models Easily," Discussion paper.

Varejão, J., And P. Portugal (2006): "Employment Dynamics and the Structure of Labor Adjustment Costs," Iza discussion papers, Institute for the Study of Labor (IZA).

Veracierto, M. L. (2002): "Plant-Level Irreversible Investment and Equilibrium Business Cycles," American Economic Review, 92(1), 181-197.

Wen, Y. (1998): "Can a real business cycle model pass the Watson test?," Journal of Monetary Economics, 42(1), 185-203. 


\section{Tables}

\begin{tabular}{|c|c|l|}
\hline \hline Parameters & Values & Interpretation \\
\hline$\beta$ & 0.9902 & Annual real rate 4\% \\
$\delta$ & 0.025 & Annual depreciation rate 10\% \\
$b$ & 0.329 & To match capital to output ratio of 2.35(Thomas and Khan $(2004))$ \\
$a$ & 0.58 & Labor's share of output $($ King, Plosser, and Rebelo $(1988))$ \\
$\eta$ & 1 & log $C_{t}$, common in the literature \\
$\phi$ & 0.25 & On average one quarter of the time are allocated to productive \\
& & activities(Benhabib \& Farmer,1992) \\
$\lambda$ & 1.38 & Average duration of employment of 4.35 quarters $(\alpha=0.77)$ \\
$\tau$ & 1.2 & Increasing hazard function Varejão and Portugal $(2006)$ \\
$\varsigma$ & 0.95 & Solow residual estimate, \\
$\sigma^{2}$ & 0.007 & Solow residual estimate, \\
\hline \hline
\end{tabular}

Table 2: Calibration Values

\begin{tabular}{l|c|c|cccc}
\hline \hline \multirow{2}{*}{ Variables } & Standard & Relative & \multicolumn{5}{|c}{ Cross } & Correlation with output \\
\cline { 1 - 2 } Hours* & Deviation\% & S.D. & -3 & -2 & -1 & 0 \\
Employment* & 1.69 & 0.98 & 0.38 & 0.54 & 0.78 & 0.92 \\
Real wage & 1.41 & 0.82 & 0.22 & 0.47 & 0.72 & 0.89 \\
Consumption & 0.76 & 0.44 & 0.47 & 0.58 & 0.66 & 0.68 \\
Output & 1.27 & 0.74 & 0.57 & 0.72 & 0.82 & 0.83 \\
Investment & 1.72 & 1.00 & 0.38 & 0.63 & 0.85 & 1.00 \\
Labor productivity & 5.34 & 3.10 & 0.43 & 0.63 & 0.82 & 0.90 \\
& 0.73 & 0.42 & 0.44 & 0.45 & 0.34 & 0.34 \\
\hline
\end{tabular}

Notes: all statistics are reported in Cooley (1995) Table(1.1)

*: Based on establishment survey.

Table 3: Business Cycle Statistics for the U.S. Economy 


\begin{tabular}{l|c|c|cccc}
\hline \hline & Standard & Relative & \multicolumn{5}{|c}{ Cross Correlation with output } \\
\cline { 1 - 5 } Variables & Deviation\% & S.D. & -3 & -2 & -1 & 0 \\
\hline Labor & 0.60 & 0.49 & 0.34 & 0.47 & 0.71 & 0.95 \\
Capital & 0.31 & 0.25 & -0.34 & -0.17 & 0.05 & 0.31 \\
Real wage & 0.50 & 0.40 & 0.10 & 0.34 & 0.62 & 0.97 \\
Consumption & 0.36 & 0.29 & 0.10 & 0.34 & 0.62 & 0.94 \\
Output & 1.23 & 1.00 & 0.30 & 0.50 & 0.74 & 1.00 \\
Interest rate & 0.03 & 0.03 & 0.42 & 0.60 & 0.79 & 0.94 \\
Investment & 3.32 & 2.77 & 0.35 & 0.56 & 0.78 & 0.99 \\
Labor productivity & 0.67 & 0.54 & 0.28 & 0.50 & 0.73 & 0.97 \\
\hline
\end{tabular}

Table 4: Business Cycle Statistics for the Calvo-adjustment RBC Model

\begin{tabular}{l|c|c|cccc}
\hline \hline \multirow{2}{*}{ Variables } & Standard & Relative & \multicolumn{5}{|c}{ Cross } & Correlation with output \\
Labor & Deviation\% & S.D. & -3 & -2 & -1 & 0 \\
\hline Capital & 2.13 & 1.01 & 0.32 & 0.53 & 0.76 & 0.99 \\
Real wage & 0.51 & 0.25 & -0.35 & -0.18 & 0.05 & 0.32 \\
Consumption & 0.92 & 0.44 & -0.01 & 0.21 & 0.53 & 0.98 \\
Output & 0.45 & 0.21 & -0.01 & 0.21 & 0.53 & 0.84 \\
Interest rate & 2.09 & 1.00 & 0.24 & 0.48 & 0.75 & 1.00 \\
Investment & 0.06 & 0.03 & 0.37 & 0.56 & 0.79 & 0.97 \\
Labor productivity & 6.09 & 2.91 & 0.28 & 0.49 & 0.78 & 1.00 \\
& 0.39 & 0.20 & -0.29 & -0.11 & 0.16 & 0.41 \\
\hline
\end{tabular}

Table 5: Business Cycle Statistics for the Weibull-Adjustment RBC Model 


\section{SFB 649 Discussion Paper Series 2008}

For a complete list of Discussion Papers published by the SFB 649, please visit http://sfb649. wiwi. hu-berlin.de.

001 "Testing Monotonicity of Pricing Kernels" by Yuri Golubev, Wolfgang Härdle and Roman Timonfeev, January 2008.

002 "Adaptive pointwise estimation in time-inhomogeneous time-series models" by Pavel Cizek, Wolfgang Härdle and Vladimir Spokoiny, January 2008.

003 "The Bayesian Additive Classification Tree Applied to Credit Risk Modelling" by Junni L. Zhang and Wolfgang Härdle, January 2008.

004 "Independent Component Analysis Via Copula Techniques" by Ray-Bing Chen, Meihui Guo, Wolfgang Härdle and Shih-Feng Huang, January 2008.

005 "The Default Risk of Firms Examined with Smooth Support Vector Machines" by Wolfgang Härdle, Yuh-Jye Lee, Dorothea Schäfer and Yi-Ren Yeh, January 2008.

006 "Value-at-Risk and Expected Shortfall when there is long range dependence" by Wolfgang Härdle and J ulius Mungo, Januray 2008.

007 "A Consistent Nonparametric Test for Causality in Quantile" by Kiho Jeong and Wolfgang Härdle, January 2008.

008 "Do Legal Standards Affect Ethical Concerns of Consumers?" by Dirk Engelmann and Dorothea Kübler, January 2008.

009 "Recursive Portfolio Selection with Decision Trees" by Anton Andriyashin, Wolfgang Härdle and Roman Timofeev, January 2008.

010 "Do Public Banks have a Competitive Advantage?" by Astrid Matthey, January 2008.

011 "Don't aim too high: the potential costs of high aspirations" by Astrid Matthey and Nadja Dwenger, January 2008.

012 "Visualizing exploratory factor analysis models" by Sigbert Klinke and Cornelia Wagner, January 2008.

013 "House Prices and Replacement Cost: A Micro-Level Analysis" by Rainer Schulz and Axel Werwatz, January 2008.

014 "Support Vector Regression Based GARCH Model with Application to Forecasting Volatility of Financial Returns" by Shiyi Chen, Kiho Jeong and Wolfgang Härdle, January 2008.

015 "Structural Constant Conditional Correlation" by Enzo Weber, January 2008.

016 "Estimating Investment Equations in Imperfect Capital Markets" by Silke Hüttel, Oliver Mußhoff, Martin Odening and Nataliya Zinych, January 2008.

017 "Adaptive Forecasting of the EURIBOR Swap Term Structure" by Oliver Blaskowitz and Helmut Herwatz, January 2008.

018 "Solving, Estimating and Selecting Nonlinear Dynamic Models without the Curse of Dimensionality" by Viktor Winschel and Markus Krätzig, February 2008.

019 "The Accuracy of Long-term Real Estate Valuations" by Rainer Schulz, Markus Staiber, Martin Wersing and Axel Werwatz, February 2008.

020 "The Impact of International Outsourcing on Labour Market Dynamics in Germany" by Ronald Bachmann and Sebastian Braun, February 2008.

021 "Preferences for Collective versus Individualised Wage Setting" by Tito Boeri and Michael C. Burda, February 2008.

\section{SFB 649, Spandauer Straße 1, D-10178 Berlin} http:/ / sfb649.wiwi.hu-berlin.de

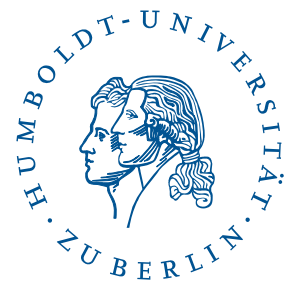


022 "Lumpy Labor Adjustment as a Propagation Mechanism of Business Cycles" by Fang Yao, February 2008. 